\section{rev Psi}

Revista de Psicología (UNLP)

https://revistas.unlp.edu.ar/revpsi

\title{
Memoria emocional. Una revisión sistemática sobre la capacidad modulatoria de la música, la actividad física y el bilingüismo
}

\author{
Veronika Diaz Abrahan ${ }^{1,2}$ \\ María Benítez ${ }^{1,2,3}$ \\ Maximiliano Bossio $0^{1,2,3}$ \\ Nadia Justel ${ }^{1,2}$ \\ Leticia Sarli ${ }^{1,2,3}$
}

\section{Correspondencia}

abrahanveronika@conicet.gov.ar

Filiaciones institucionales

${ }^{1}$ Laboratorio Interdisciplinaria de Neurociencia

Cognitiva (LINC). Centro de Estudios

Multidisciplinarios en Sistemas Complejos y Ciencias del Cerebro (CEMSC3), Instituto de Ciencias Físicas (ICIFI), Escuela de Ciencia y Tecnología (ECyT), Universidad Nacional de San Martín (Argentina)
${ }^{2}$ Consejo Nacional de Investigaciones Científicas y Técnicas (CONICET) (Argentina)

${ }^{3}$ Universidad Nacional de Córdoba (Argentina)

\section{Resumen}

La memoria emocional se define como aquella información que se encuentra almacenada en nuestro sistema de modo duradero debido a que en su adquisición, consolidación o recuperación estuvo acompañada de un nivel alto y óptimo de activación fisiológica. Hay diversos modos de modular la memoria emocional. En la presente revisión teórica se indagan tres factores que modulan la memoria con contenido emocional pero que no han sido vastamente estudiados: la música, la realización de actividad física y la adquisición de otro idioma. A través de una búsqueda sistematizada de artículos en revistas científicas indexadas en bases de datos, se seleccionaron 21 artículos (8 sobre música, 7 referidos a la actividad física y 6 sobre bilingüismo). Como conclusión general se destaca que las intervenciones ambientales examinadas, tienen la capacidad de modular la memoria emocional, cada una alterando un tipo particular de contenido emocional, ya sea visual y/o verbal.

\section{Palabras clave}

memoria | emoción | música | actividad física | bilingüismo

\section{Cómo citar}

Diaz Abrahan, V., Benitez, M., Bossio, M., Sarli, L. y Justel, N. (2021). Memoria emocional. Una revisión sistemática sobre la capacidad modulatoria de la música, la actividad física y el bilingüismo. Revista de Psicología, 20(1), 193-220. doi: 10.24215/2422572XE068

\section{Recibido}

08 mar. 2020

Aceptado

Publicado

27 oct. 2020

Coordinadora del dossier

Marina Trakas (Instituto de Investigaciones Filosóficas, Sociedad de Análisis Filosófico, IIF-SADAF, Argentina)
ISSN

2422-572X

\section{Licencia}

Licencia de Cultura Libre CC-BY 4.0

(Compartir - Adaptar - Atribuir)

Entidad editora

RevPsi es una publicación de la Facultad de Psicología (Universidad Nacional de La Plata, Argentina) 


\section{Memória emocional. Uma revisão sistemática da capacidade moduladora da música, atividade física e bilinguismo}

\section{Resumo}

A memória emocional é definida como a informação que é encontrada em nosso sistema de maneira duradoura devido ao acompanhamento das emoções, seja na aquisição, consolidação ou recuperação. Existem várias maneiras de modular a memória emocional. Nesta revisão teórica, três fatores que modulariam a memória com conteúdo emocional são investigados, mas ainda não foram amplamente estudados: música, atividade física e aquisição de outro idioma. Por meio de busca sistemática de artigos em revistas científicas indexadas em bases de dados, foram selecionados 22 artigos ( 9 sobre música, 7 referentes à atividade física e 6 sobre bilinguismo). Como conclusão geral, note-se que as intervenções ambientais examinadas têm a capacidade de modular a memória emocional, cada uma alterando um tipo específico de conteúdo emocional, seja visual e / ou verbal.

\section{Palavras-chave}

memória | emoção | música | atividade física | bilinguismo

\section{Emotional memory. A systematic review of the modulatory capacity of music, physical activity and bilingualism}

\section{Abstract}

The emotional memory is defined as that information that is stored in our system in a durable way because in its acquisition, consolidation or recovery it was accompanied by an optimal and high level of physiological activation. This theoretical review looks into three factors that could also modulate memory with emotional content but have not been thoroughly studied: music, physical activity and the acquisition of a second language. Through a systematic search of articles on indexed scientific journals, 22 articles were selected ( 9 regarding music, 7 regarding physical activity, and 6 regarding bilingualism). As a general conclusion, each environmental intervention shows emotional memory modulation, modifying a particular type of emotional content (visual and/or verbal).

\section{Keywords}

memory | emotion | music | physical activity | bilingualism 
Los sistemas de memoria permiten a los seres humanos almacenar los acontecimientos y las situaciones que aprenden a lo largo de la vida, para luego recuperarlos con objetivos particulares, adaptándose mejor a situaciones futuras (Squire, 1987, 2004). Desde una perspectiva funcional, estos sistemas se conciben como un constructo complejo que requiere diferentes procesos, con particularidades psicológicas y neurobiológicas (McGaugh, 2002), susceptible de modificación dependiendo de factores biológicos, por ejemplo el ciclo menstrual (Andreano et al., 2008), así como ambientales, entre los que se puede nombrar al estilo de vida y las actividades que las personas realizan (Diaz Abrahan y Justel, 2019; Diaz Abrahan, Bossio et al., 2019). Este proceso de modificación se denomina modulación de la memoria (Roozendaal y McGaugh, 2011).

En función del curso temporal de la traza mnémica, es decir de acuerdo al tiempo en el que la información adquirida es accesible al recuerdo, existe un tipo de memoria denominado de largo plazo (Atkinson y Shiffrin, 1971), que permite almacenar gran cantidad de información durante períodos prolongados de tiempo, variando su extensión desde horas, días, meses, hasta años, y en algunos casos, toda la vida (Milner et al., 1998; Ruetti et al., 2009; Tulving, 2002). Dentro de este sistema, la memoria para experiencias de eventos específicos y únicos (la cual refiere al aprendizaje a través de una única exposición), generalmente asociadas con un tiempo, lugar y emoción en particular, refieren a la memoria de tipo episódica (Tulving, 2002). Como una subdivisión de dicha memoria, existe un tipo particular denominada emocional, caracterizada por aquella información que estuvo acompañada por factores activadores o estresantes al momento de su adquisición, consolidación o recuperación (Bermúdez-Rattoni y Prado-Alcalá, 2001) y que resulta en un mayor recuerdo y detalle de estímulos afectivos por sobre los neutros (Bradley et al., 1992; Cahill y McGaugh, 1995, 1998; Cahill y van Stegeren, 2003; Erk et al., 2010; McGaughy Roozendaal, 2009). En este sentido, el contenido emocional presente en una situación actúa como un modulador ya sea en la codificación, consolidación o recuperación de la información aprendida (LaBar y Cabeza, 2006).

Existen investigaciones que consideran dos dimensiones ortogonales básicas en el estudio de la memoria emocional: la excitación o arousal (nivel de activación fisiológica) y la valencia (valoración positiva o negativa) (Lang et al., 1993; Russell, 1980). Estos trabajos hacen uso de diversos estímulos y paradigmas (imágenes, videos o lista de palabras con contenido emocional vs. neutro), e implementan diferentes metodologías de investigación en distintas situaciones (tanto experimentales como cotidianas), para estudiar los mecanismos y los factores que se relacionan a la memoria emocional en los distintos momentos del desarrollo humano (Cordon et al., 2013; Roozendaal y McGaugh, 2011).

Algunos estudios mostraron que el nivel de arousal puede afectar la memoria de corto y largo plazo (Moayeri et al., 2010) y la memoria emocional no es la excepción (Justel et al., 2013). El nivel de excitación o arousal puede interferir en cada una de las etapas de procesamiento de la información, es decir adquisición (presencia de factores 
emocionales antes o durante el aprendizaje de información, Tambini et al., 2017), consolidación o almacenamiento (ante la presencia de factores emocionales después del aprendizaje de información, Shields et al., 2017); recuperación (ante la presencia de factores emocionales antes o durante la evocación de información, LaBar y Cabeza, 2006) así como reconsolidación (luego de la reactivación de la traza mnémica, Piñeyro et al., 2018). Específicamente en relación a la memoria emocional, se identifican diversos modos de modularla, dentro de los más conocidos y estudiados se encuentra el estrés (Wangy Sun, 2016) así como los patrones de sueño (Diekelmann y Born, 2010) y descanso (Wamsley, 2019). En este sentido, algunos entrenamientos y factores ambientales fueron identificados por sus potencialidades modulatorias de la memoria, entre los que se puede nombrar a la música (Diaz Abrahan y Justel, 2019), al entrenamiento físico (Keyan y Bryant, 2017b) y el aprendizaje de un segundo idioma (Ferré et al., 2019).

La importancia de recopilar y analizar investigaciones abocadas al estudio del efecto de ciertos factores ambientales a nivel cognitivo radica en el hecho de que los informes de la Organización Mundial de la Salud (OMS, 2020) indican que la población de adultos mayores de 60 años aumentará significativamente en las próximas décadas. Este favorable aumento en la expectativa de vida podría traer aparejado un incremento en el número de individuos afectados por deterioro a nivel cognitivo (Tsai et al., 2015), especialmente en población adulta mayor (Kamijo et al., 2009), expresando un declive de las funciones mnémicas, los procesos de aprendizaje y el funcionamiento ejecutivo (Chuang et al., 2015). En este sentido, los tres factores ambientales desarrollados en la presente revisión representan modelos de intervención a bajo costo, aplicable a diversas poblaciones, y que carece de los efectos indeseados que normalmente acompañan a los tratamientos farmacológicos (Diaz Abrahan, Bossio et al., 2019; Erikson et al., 2011; Frutos Lucas et al., 2018), aspectos ciertamente relevantes para nuestro contexto latinoamericano.

Las demandas del sistema nervioso son específicas de cada tipo de factor ambiental, sin embargo, dentro de la literatura existen numerosos estudios que comparan los correlatos neuroanatómicos y las repercusiones cognitivas compartidos entre la música y la adquisición de una segunda lengua por un lado (Vaquero et al., 2020), y la música y la realización de actividad física por el otro (Clark et al., 2013). Por tal motivo, el objetivo de la presente revisión es recopilar y describir los estudios que muestran la manera en que la memoria, especialmente aquella que refiere a contenidos mnémicos asociados a dimensiones emocionales, puede ser modulada mediante factores ambientales como la música, la actividad física y la adquisición de una segunda lengua.

\section{Metodología implementada}

Se realizó un estudio retrospectivo de la literatura sobre la utilización de tres factores ambientales: la música, la actividad física y la adquisición de un segundo idioma (bilingüismo). Estos tres factores fueron abordados desde dos perspectivas diferentes: por un lado, como estilos de vida (es decir, actividades que las personas realizan de forma prolongada a lo largo de su vida), y por otro lado, como posibles 
intervenciones ambientales no invasivas que modularían la memoria emocional de diferentes poblaciones (niños, adultos jóvenes y mayores).

Se ejecutó una revisión de la bibliografía en las bases de datos Redalyc, SciELO, Science Direct, PubMed, y Taylor \& Francis. En cada uno de los buscadores académicos se utilizaron, en una primera instancia, las siguientes palabras claves: music, musical training, physical activity, aerobic exercise, physical exercise, bilingualism. memory, emotional memory, modulation. Se combinaron los operadores booleanos AND y $\mathrm{OR}$, según conveniencia.

Los criterios de búsqueda utilizados para filtrar los resultados en función de la temática de la revisión fueron: (a) que se trate de investigaciones empíricas, (b) que el artículo plantee una relación entre la memoria emocional y música/actividad física/ bilingüismo; o (c) que se indague el efecto de la implementación de una propuesta basada en la música, la actividad física y/o el bilingüismo, en relación a la memoria emocional; (d) que contenga las palabras claves para los términos relevantes en español/inglés; y (e) que haya sido publicado en los últimos 20 años.

Una primera búsqueda arrojó 9832 resultados, de los cuales se seleccionaron 548 artículos considerados adecuados luego de la lectura del título de cada uno. A partir de la lectura del resumen/abstract de cada artículo se estableció un total de 89 publicaciones que cumplían con los criterios de inclusión, y mediante un último filtro determinado por la lectura completa del manuscrito, se seleccionaron 21 artículos empíricos que conformaron la muestra final: ocho sobre música, siete sobre actividad física y seis sobre bilingüismo.

Para su análisis final, cada artículo fue interpretado independientemente utilizando un enfoque cualitativo, identificando categorías teóricas derivadas de los datos mediante la utilización de un método comparativo constante, teniendo en cuenta las siguientes variables de análisis: (a) temática de la investigación; (b) población de estudio, (c) comparaciones metodológicas realizadas, (d) variables dependientes; (d) instrumento de evaluación utilizado y (e) resultados obtenidos. En la Figura 1 se observa el diagrama de flujo de la selección de los artículos.

\section{Principales resultados}

En la Tabla 1 se detalla el total de los artículos seleccionados en relación a la música, la actividad física y el bilingüismo.

\section{Música}

Las demandas del sistema nervioso por parte de la música son únicas y brindan a las personas una experiencia multisensorial excepcionalmente rica (Sachs et al., 2019; Vaquero et al., 2018; Zatorre et al., 2007). La exposición a un estímulo musical mejora el desempeño de funciones cognitivas, gracias a la modificación afectiva, emocional y fisiológica que la música induce, entre las cuales se destaca la memoria (Altenmüller y Schlaug, 2015; Christie et al., 2017; Strong y Mast, 2018). 


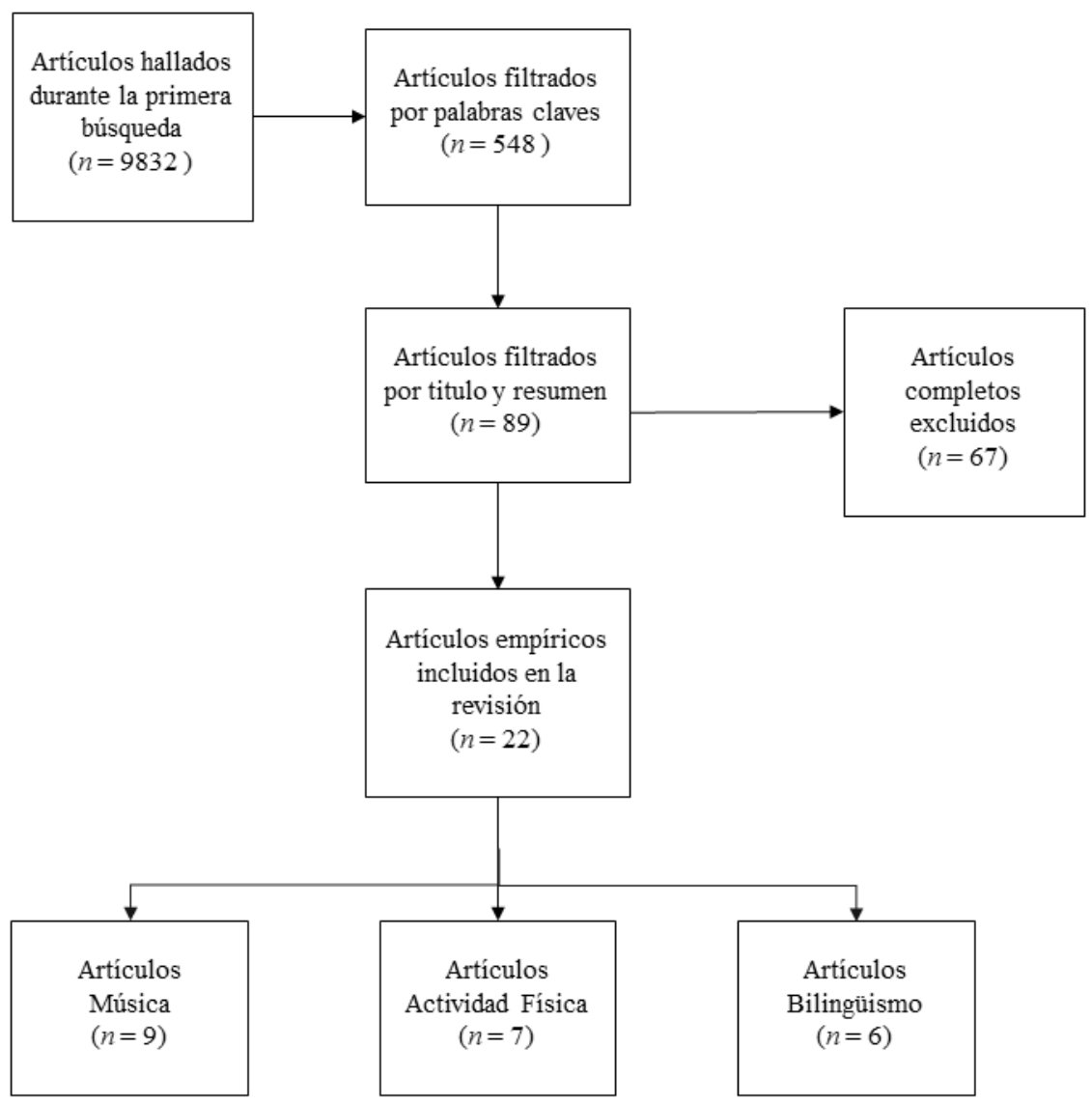

Figura 1. Flujo de selección de los artículos. Fuente: Elaboración propia

Este efecto neurofisiológico es la causa por la cual se ha podido establecer una estrecha relación entre la música, la memoria y las emociones (Diaz Abrahan et al., 2018; Diaz Abrahan, Shifres et al., 2019; Diaz Abrahan y Justel, 2019; Judde y Rickard, 2010; Justel y Rubinstein, 2013; Rickard et al., 2012). A partir de la búsqueda bibliográfica realizada se encontraron ocho estudios que cumplían con los criterios de inclusión, los cuales serán desarrollados a continuación.

Las investigaciones en torno a esta temática se caracterizan por la implementación de propuestas musicales, en su mayoría intervenciones agudas, en diferentes fases de la formación de la memoria emocional, exceptuando un estudio donde se implementó un programa de aprendizaje musical. En esta línea de desarrollo, los estudios pueden dividirse según se trate de propuestas de percepción musical, es decir ante la escucha de una pieza musical (Judde y Rickard, 2010; Musiek et al., 2005), o de producción musical, tratándose de actividades que implican la creación, improvisación o reproducción musical utilizando diferentes elementos musicales (Gerry et al., 2012). 


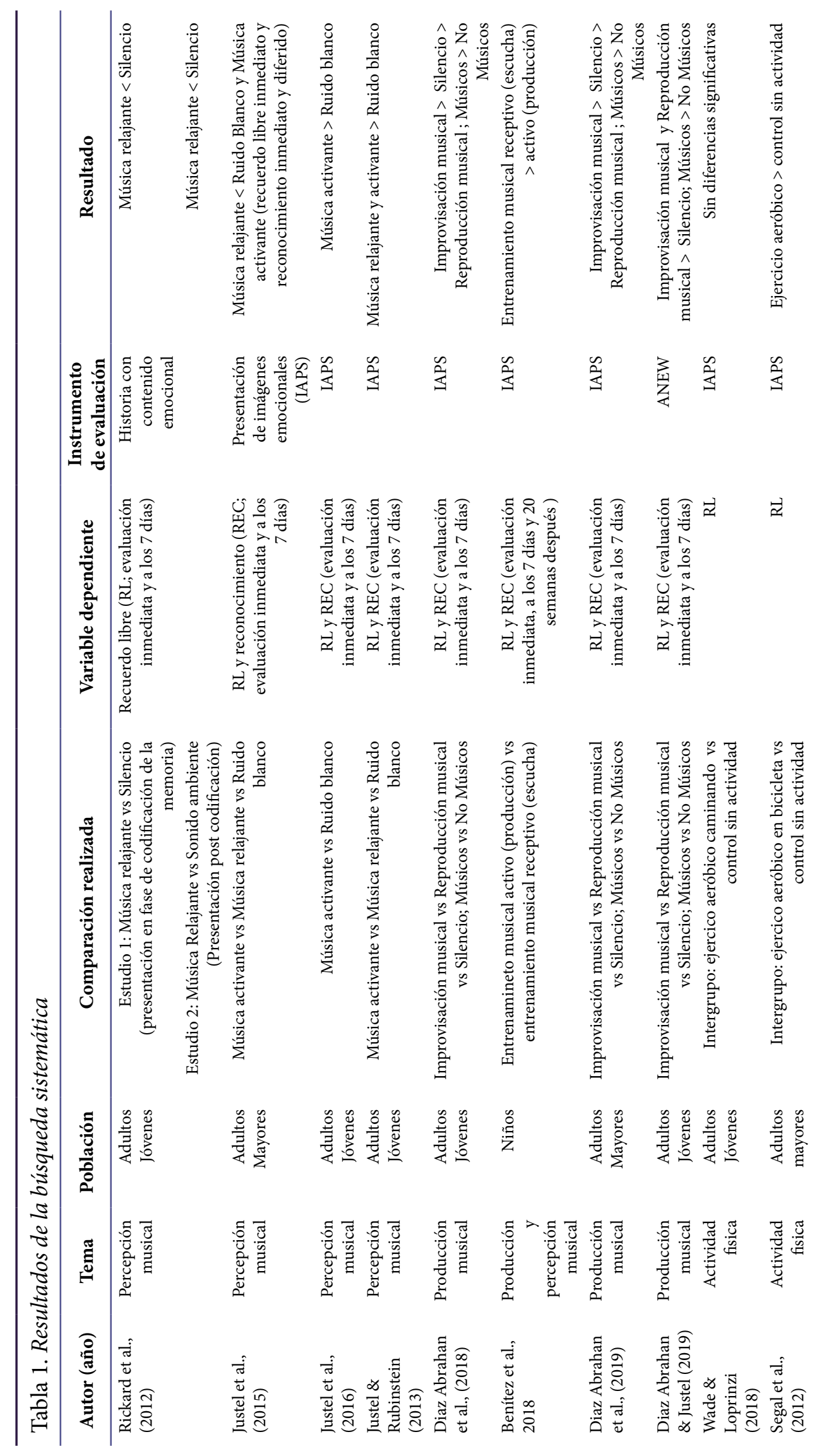




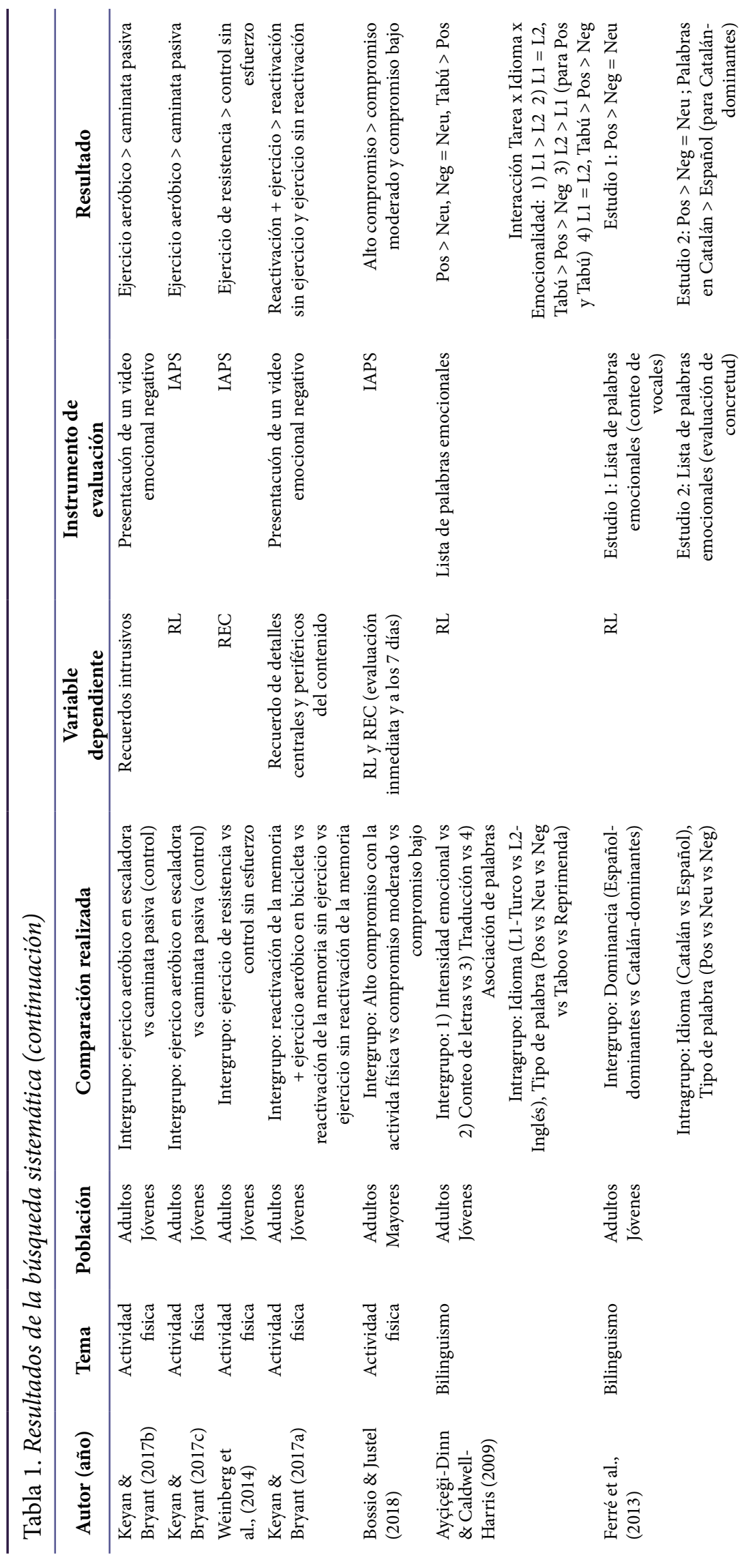




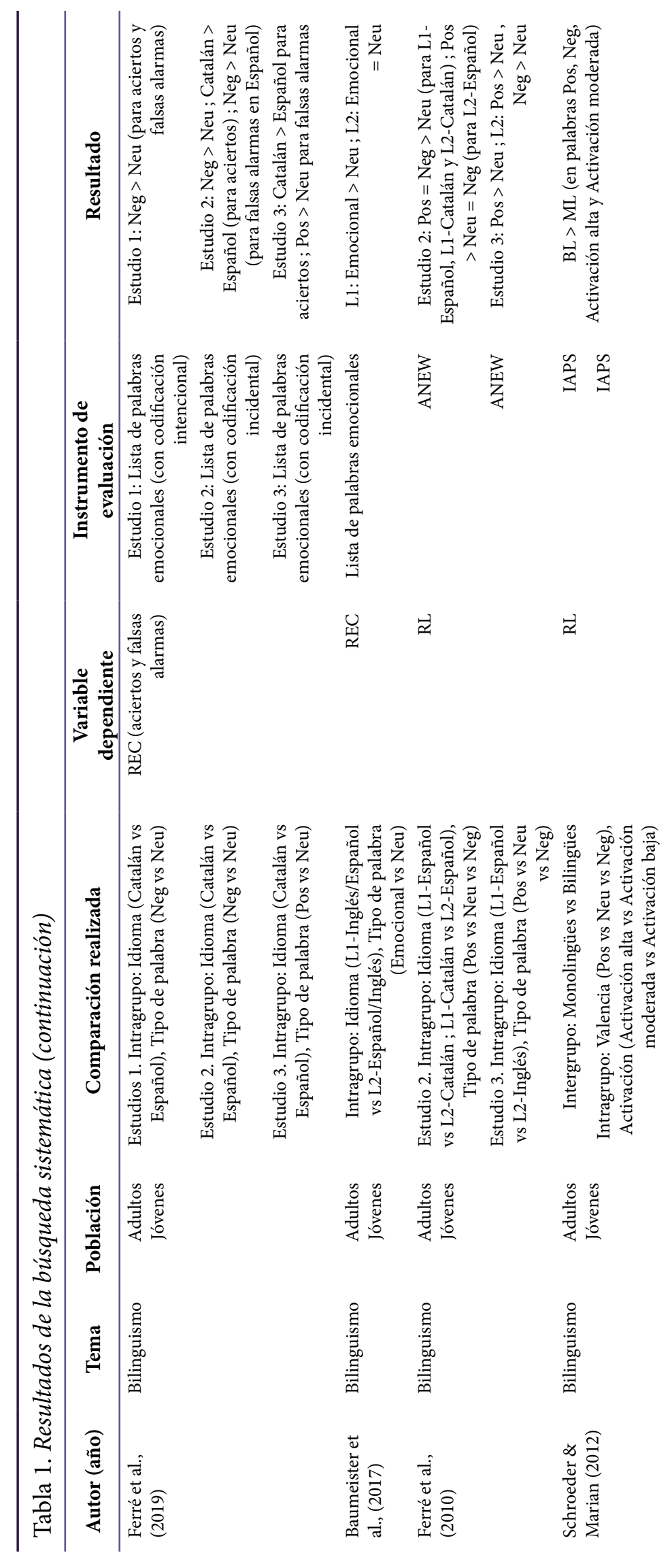


En relación a la percepción musical, los estudios y los resultados obtenidos se diferencian dependiendo del uso de piezas musicales que generan una activación psicofisiológica, es decir, piezas con modalidades armónicas mayores, ritmos rápidos, timbres estridentes, con presencia de estructuras musicales que rompen con la expectativa del oyente (Grocke y Wigram, 2007; Justel et al., 2016), o de aquellas denominadas relajantes, i.e. piezas con modalidades armónicas menores, ritmos lentos, timbres cálidos (Grocke y Wigram, 2007; Knight y Rickard, 2001; Rickard et al., 2012). En relación a este tópico, Rickard et al. (2012), realizaron dos experimentos en donde demostraron el uso de música relajante como un medio para reducir los niveles de excitación, desafiando así el efecto de la emoción asociado al recuerdo de una experiencia. Para ello, expusieron a adultos jóvenes a una historia con contenido emocional negativo o una neutro y de forma simultánea (en la adquisición/codificación de información) o posteriormente (consolidación de la información) a la presentación de la historia los participantes escucharon música con características psicofisiológicas relajantes o sonidos del ambiente (condición control). Al evaluar el recuerdo a través de una tarea de reconocimiento, los autores observaron que aquellos grupos de participantes expuestos a la condición control tuvieron un mayor recuerdo de lo emocional sobre lo neutro (resultado esperado de acuerdo a la literatura sobre el tema). Sin embargo, los participantes expuestos a música relajante no presentaron diferencias en la evocación de contenido de la historia neutra y la emocional, lo que indicaría que la música interfirió sobre el efecto habitual que ejerce la activación emocional sobre la adquisición de información. Resultados similares, pero con adultos mayores, fueron hallados por Justel et al., (2015), quienes pusieron a prueba la percepción de música activante vs. relajante vs. ruido blanco sobre la fase de consolidación de una memoria emocional visual. Los investigadores encontraron un menor rendimiento en el recuerdo libre inmediato y el reconocimiento inmediato y diferido del material adquirido, por parte de los adultos que escucharon la pieza relajante, sin encontrar diferencias entre el ruido blanco y la música activante.

Por el contrario, las piezas musicales con características activantes muestran el efecto opuesto. Bajo la metodología implementada en los estudios previos, Justel y Rubinstein (2013) evaluaron el efecto modulador de la percepción musical sobre una memoria visual emocional. Las autoras encontraron que los participantes que escucharon una pieza musical activante tuvieron un mejor recuerdo de contenido neutral y emocional, que los participantes que escucharon la pieza relajante y el ruido blanco. Resultados similares fueron encontrados al evaluar una memoria verbal emocional (Justel et al., 2016). En este segundo trabajo, el equipo de investigación indagó si la escucha de una pieza musical con características activantes afectaba la consolidación de una lista de palabras. Los adultos jóvenes que participaron del estudio debían leer y oír una serie de palabras neutrales y emocionales (a través del uso de la adaptación al español del ANEW, Affective Norms for English Words, Redondo et al., 2007). De manera inmediata los participantes fueron divididos aleatoriamente en dos grupos: uno de ellos fue expuesto a ruido blanco, y el otro, a 
música activante. Al evaluar el recuerdo libre y el reconocimiento de las palabras, tanto de forma inmediata como diferida a la tarea de adquisición de información, los participantes expuestos a la pieza musical activante tuvieron un mejor recuerdo de contenido neutral y emocional, tanto a corto como a largo plazo.

Algunas de las explicaciones en torno a los resultados de los estudios presentados radica en el hecho de que el arousal emocional inducido musicalmente se encuentra acompañado por la liberación de neuroquímicos que modulan el desempeño cognitivo, así como por la liberación de neurotransmisores involucrados en los mecanismos de recompensa y de placer (Chanda y Levitin, 2013), los cuales inducen estados emocionales y afectivos que resultarían en el refuerzo de los procesos de formación de la memoria (Ferreri y Rodriguez-Fornells, 2017; Rickard et al., 2012; Rickard et al., 2005).

Por otra parte, dentro del conjunto de las investigaciones halladas, se destacan aquellas que implican actividades de producción musical, las cuales presentan una temática de investigación novedosa, ya que son propuestas destinadas a personas con o sin conocimientos musicales. Siguiendo la lógica de la implementación de un tratamiento musical posterior al período de adquisición de información, Diaz Abrahan et al. (2018) realizaron un estudio poniendo a prueba la eficacia de la improvisación musical como modulador cognitivo, actividad que fue implementada como un juego de creación sonoro-musical. Los participantes, adultos jóvenes músicos y no músicos, observaron una serie de imágenes, a través del uso del protocolo de imágenes afectivas (IAPS, por sus siglas en inglés, International Affective Picture System; Lang et al., 1995), y posteriormente fueron divididos aleatoriamente y expuestos a tres condiciones diferentes: improvisación musical libre, reproducción de un patrón rítmico o permanencia en silencio. Los autores encontraron que las personas que participaron de la improvisación recordaron más información tanto neutra como emocional en comparación a los otros grupos. Resultados similares fueron hallados en una investigación con adultos mayores (Diaz Abrahan, Shifres et al., 2019).

Las explicaciones que respaldan el efecto de la improvisación musical sobre la memoria emocional también se relacionan con la emergencia de estados emocionales producto de la participación en actividades de creación musical. Existen algunos estudios que postulan que la activación emocional inducida a través de la implementación de un tratamiento, luego de la codificación de información, mejora la memoria de contenido positivo y negativo por sobre el neutro (Cahill y McGaugh, 1995, 1998; Cordon et al., 2013). Sin embargo, en los estudios citados previamente las intervenciones también actúan sobre contenidos neutros, aspecto que debería continuar investigándose en futuros estudios.

Aprender música por periodos cortos de tiempo también confiere ventajas cognitivas. En este sentido, la memoria es una función cognitiva que ha mostrado beneficiarse a partir del aprendizaje musical, donde se combinan la percepción y la producción musical (Talamini et al., 2018; Franklin et al., 2008). Sin embargo, esta temática presenta muy pocos antecedentes. Por ejemplo, un estudio realizado 
por Benítez et al. (2018) indagó la posible repercusión de un entrenamiento musical sobre la memoria emocional y neutra de niños en edad preescolar. Los infantes participaron de 10 semanas de entrenamiento musical especializado en percepción y producción musical. Se evaluó la memoria emocional mediante el protocolo de IAPS, en una línea de base y en dos instancias luego del período de instrucción musical (inmediatamente después del entrenamiento de 10 semanas y a las 20 semanas de finalizado el mismo). El equipo de investigadores halló que los participantes recordaron más imágenes emocionales que neutras, acorde a los antecedentes previos en adultos (Cordon et al., 2013) y que la memoria emocional fue modulada por el entrenamiento musical, siendo la modalidad perceptiva la más eficaz para consolidar el recuerdo de información.

Finalmente, en relación a la música como un estilo de vida, se han realizado estudios que evalúan participantes con entrenamiento musical, es decir personas con cinco o más años de dedicación al estudio de la música, comparándolos con grupos sin conocimiento en el área. Bajo este enfoque, estudios que incluyen el entrenamiento musical como factor de análisis han encontrado que al evaluar una memoria emocional verbal (Diaz Abrahan y Justel, 2019) y visual (Diaz Abrahan et al., 2018, Diaz Abrahan, Shifres et al., 2019) los músicos presentan un mejor rendimiento tanto inmediato a la tarea de adquisición de información, como así también siete días después. Estos estudios permiten entrever que existe un efecto por parte de las habilidades adquiridas durante el entrenamiento musical que impacta sobre la memoria emocional.

En suma, los estudios expuestos demuestran que tanto las propuestas de percepción como de producción musical tienen la capacidad de modular el recuerdo de información emocional. Esto puede deberse a que las capacidades musicales son distribuidas en ambos hemisferios cerebrales (Kotilahti et al., 2010). Las destrezas de producción y percepción musical activan diferentes áreas, corticales y subcorticales del cerebro (Nieminen et al., 2011) que, de manera solapada al procesamiento de la música, intervienen en el proceso de formación de la memoria para contenidos emocionales (Justel y Diaz Abrahan, 2012).

\section{Actividad física}

El término actividad física refiere a todos aquellos movimientos donde la puesta en marcha del sistema locomotor origina un gasto energético. Comprende tanto los entrenamientos deportivos y la ejercitación física, como a todas aquellas prácticas de la vida diaria que representen un gasto energético por encima de los niveles basales (Garber et al., 2011). Se ha visto que un estilo de vida activo favorece la memoria emocional (Bossio y Justel, 2018), pero los resultados divergen según el momento de realización de la actividad física, ya sea previos a la fase de consolidación (Wade y Loprinzi, 2018) o de manera posterior a ésta (Segal et al., 2012; Weinberg et al., 2014).

La mayoría de las investigaciones emplean metodologías basadas en entrenamientos focales, caracterizados por una única y corta exposición en el tiempo (Sellami et al., 2018). Un estudio que contó con la participación de adultos jóvenes empleó 15 
minutos de caminatas enérgicas (intensidad autodeterminada por los participantes) como intervención, y descansos sin actividad a modo de control. Los entrenamientos fueron realizados de forma previa a la observación de imágenes emocionales y neutras tomadas del IAPS. Las evaluaciones de recuerdo libre, que se efectuaron a los dos, siete y 14 días no mostraron diferencias significativas entre los grupos (Wade y Loprinzi, 2018). Estos resultados fueron explicados por los autores a través de dos ideas: por un lado, podría deberse a la alta tasa de acierto alcanzada por ambos grupos, fenómeno que podría enmascarar los beneficios del ejercicio debido a un efecto de techo del desempeño. Por otro lado, se dejó una ventana temporal de 15 minutos entre la finalización del ejercicio y el comienzo de la adquisición de información, posibilitando el retorno a valores fisiológicos basales y por ende no llegando al nivel de activación necesario para afectar la memoria.

Keyan y Bryant (2017b) también investigaron la fase de adquisición de la memoria trabajando con adultos jóvenes, implementando entrenamientos aeróbicos (prácticas cuyo sostenimiento depende principalmente de un metabolismo energético a base de oxígeno; Armstrong y Welsman, 2007). Los sujetos fueron asignados a dos condiciones: ejercicio aeróbico moderado a 60 - 85\% de la frecuencia cardíaca máxima; o una caminata sin esfuerzo significativo (control), ambas condiciones por 10 minutos. Inmediatamente después observaron imágenes positivas y negativas tomadas del IAPS. Dos días después, al evaluar el recuerdo libre, los investigadores hallaron que los sujetos del grupo aeróbico evocaron más imágenes positivas y negativas que aquellos del grupo control.

En un segundo estudio, Keyan y Bryant (2017a) pusieron a prueba las mismas intervenciones, pero implementándolas luego de la observación de un video emocional negativo, es decir evaluando la fase de consolidación. Dos días después se evaluó la memoria a través de dos tareas: recuerdo libre de detalles periféricos y centrales, así como los recuerdos intrusivos, definido por este equipo de investigadores como la aparición involuntaria de imágenes o pensamientos relacionados al material observado. Los resultados mostraron una cantidad significativamente mayor de intrusiones para el grupo expuesto al ejercicio respecto al control (Keyan y Bryant, 2017a). Estos hallazgos fueron explicados por los autores al comparar los procesos de evocación voluntaria e involuntaria: los recuerdos intrusivos se vincularían a la información con mayor impacto emocional, motivo por el cual se consolidarían más fuertemente. Como este proceso es generado por factores que también se desencadenan durante la actividad física (e.g. liberación de hormonas adrenales en sangre), se cree que la activación fisiológica del ejercicio estaría reforzando la consolidación del contenido emocional evocado involuntariamente, y medido a través de las intrusiones. Los autores explican que el ejercicio empleado no generó el nivel de activación fisiológica ideal para afectar el proceso mnémico voluntario como sí lo hizo con la memoria incidental. Una limitación de estos estudios radica en el tipo de la muestra empleado (en ambos había mayor prevalencia de mujeres que de hombres), así como la ausencia de tratamientos comparativos en cuanto a la intensidad y tipo de ejercicio, sumado a la falta de control en lo que respecta a la 
capacidad física de cada participante (Hogan et al., 2013).

Siguiendo con los estudios sobre consolidación de la memoria, Segal et al. (2012) trabajaron con adultos mayores con o sin deterioro cognitivo leve. Luego de observar una selección de imágenes con valencia positiva, fueron divididos en dos grupos: uno realizó ejercicio de intensidad moderada (grupo experimental), y el otro permaneció en descanso sin ejercitación (grupo control). Al evaluar el recuerdo libre 60 minutos después, se halló que los participantes del grupo experimental recordaban significativamente más imágenes que aquellos en el grupo control (Segal et al., 2012).

El hecho de que una amplia mayoría de estudios empleen tratamiento aeróbico se debe probablemente a los beneficios de esta modalidad asociados a la memoria. Por ejemplo, Erickson et al., (2011) hallaron que un programa de entrenamiento aeróbico de 12 meses aumentaba el volumen del hipocampo y mejoraba la memoria espacial en adultos mayores. Estas prácticas se relacionan además con un aumento en la producción de factores neurotróficos derivados del cerebro (Kennedy et al., 2017), y beneficios en los sistemas de basculación sanguínea cerebral, que favorecen la oxigenación a nivel encefálico (Frutos-Lucas et al., 2018).

Otro tipo de entrenamiento que se puede emplear es el ejercicio de resistencia que, a diferencia de las exigencias aeróbicas, se caracteriza por no generar un aumento significativo en el consumo de oxígeno (Weinberg et al., 2014).

Adultos jóvenes observaron un grupo de imágenes neutras y emocionales e inmediatamentedespuésfueron expuestosalarealización de ejercicios deestiramiento y flexión de rodillas llegando a esfuerzo máximo (para el grupo experimental), o sin carga máxima (para un grupo control). La evaluación de la memoria, realizada 48 horas después, demostró que los sujetos del grupo experimental tuvieron un reconocimiento significativamente mejor de imágenes neutras y emocionales que los del grupo control (Weinberg et al., 2014).

Un tercer estudio de Keyan y Bryant (2017c) se propuso investigar la fase de reconsolidación de la memoria. Los autores trabajaron con adultos jóvenes quienes observaron un video con contenido emocional negativo. Dos días después, los participantes atravesaron una reactivación de la memoria seguida de ejercicio (ejercicio aeróbico de intensidad moderada); una reactivación de la memoria sin ejercitación; o bien ejercicio sin reactivación. En la evaluación de la memoria que tuvo lugar tres días después se halló que, comparado con los otros dos grupos, quienes habían recibido la reactivación de la memoria y luego la ejercitación recordaban significativamente más detalles centrales del material codificado.

Finalmente, tomando la actividad física como un estilo de vida, los participantes de un estudio realizado por Bossio y Justel (2018), completaron un cuestionario por auto-reporte, dando cuenta de la cantidad y tipo de actividades físicas que realizaban en forma habitual. Se evaluó la memoria emocional mediante el protocolo del IAPS, investigando tanto recuerdo libre como reconocimiento (de modo inmediato y diferido). Se halló que, en las evaluaciones inmediatas, los sujetos que poseían los 
niveles más altos de compromiso con la actividad física recordaban mayor cantidad de imágenes positivas que los sujetos con compromiso moderado o bajo, teniendo además los mejores desempeños en la tarea de reconocimiento. Adicionalmente, y con el fin de extender la exploración en esta área, los autores plantearon futuras líneas de trabajo considerando otras variables que podrían modular los desempeños (e.g. calidad de vida percibida, dieta, ciclos de sueño), así como la posibilidad de incorporar métodos de división por grupo basados en la capacidad cardiorrespiratoria de los participantes.

Como se ha visto, las metodologías implementadas varían en cuanto al momento de exposición al ejercicio, estímulos emocionales empleados, método de evaluación, población estudiada y tipo de tratamientos. Cuando la actividad física se realiza de forma previa a la codificación, los resultados son contradictorios, ya que han mostrado tanto modular favorablemente el recuerdo (Keyan y Bryant, 2017b), como no poseer efectos significativos (Wade y Loprinzi, 2018). Por el contrario, según los estudios citados (Keyan y Bryant, 2017a; Segal et al., 2012; Weinberg et al., 2014), la exposición al ejercicio luego de la adquisición de información acarrea en todos los casos una mejora del desempeño mnémico. Además, los ejercicios de resistencia demostraron ser favorables (Weinberg et al., 2014), así como los tratamientos que modularon el proceso de reconsolidación (Keyan y Bryant, 2017c). Finalmente, sujetos con estilos de vida más activos mostraron mejores desempeños mnémicos que aquellos más sedentarios (Bossio y Justel, 2018). Aunque aún es necesario realizar más investigaciones, los estudios presentados dan cuenta de un efecto beneficioso de la actividad física sobre la memoria cuando el ejercicio acompaña el proceso de formación de los recuerdos.

\section{Bilingüismo}

En este apartado se presentarán aquellos estudios centrados en el aprendizaje de información emocional en personas bilingües (BL), es decir en personas que utilizan diariamente dos o más idiomas (Grosjean, 2008, 2013). Como población, los BL presentan una gran variabilidad producto de las diferencias en la historia lingüística personal (Haranto y Yang, 2016; Yow y Li, 2015). En rasgos generales, los BL se clasifican en dos grandes grupos, de acuerdo a la edad en la que adquirieron sus idiomas: los BL secuenciales y los BL simultáneos. El primer grupo refiere a quienes han adquirido un segundo idioma (L2) de forma posterior a su idioma materno (L1) $y$, por lo tanto, presentan asimetrías en el dominio de ambos idiomas. El segundo grupo, en cambio, comprende a quienes adquirieron dos idiomas de forma conjunta y presentan un dominio similar en cada uno.

La literatura en el área indica que los BL presentan una menor emocionalidad cuando producen o perciben en su L2 en comparación con su L1 (Pavlenko, 2005, 2012). Por este motivo, en el área de la memoria episódica, el interés se centra en identificar los cambios que se producen en el almacenamiento y la evocación de información cuando ésta es presentada en los diversos idiomas que el BL utilice (Anooshian y Hertel, 1994; Ayçiçeği y Harris, 2004; Francis y Gutiérrez, 2012). A partir de la búsqueda realizada se encontraron seis estudios que cumplían con los criterios de inclusión. 
En primer lugar, tres estudios proponen que la tarea ejecutada por los participantes en el momento de la codificación puede dar cuenta de las diferencias en el recuerdo entre ambos idiomas. A este fin, Ayçiçeği-Dinn y Caldwel-Harris (2009) evaluaron el recuerdo de palabras con diferentes cargas emocionales (palabras positivas, neutras, negativas, tabúes y reprimendas) en BL secuenciales. Para ello, separaron la muestra en cuatro grupos a quienes les dieron cuatro instrucciones diferentes para la fase de codificación: unos debían evaluar qué tan intenso era el estímulo; otros, la cantidad de letras de cada palabra; el tercero, reportar la traducción del estímulo presentado; y el cuarto, reportar palabras asociadas al estímulo. Posteriormente, todos realizaron una tarea de recuerdo libre. Cuando los participantes debían evaluar la intensidad emocional de los estímulos, los autores encontraron que se recordaron mayor cantidad en L1 que en L2 de todos los tipos palabras. Sin embargo, cuando se solicitaba a los participantes responder con la traducción del estímulo observado, recordaron más palabras positivas y tabúes en L2 que en L1. Para los otros dos grupos, los autores no hallaron diferencias en el recuerdo de L1 y L2. Por lo tanto, concluyeron que sólo las tareas que requieren una mayor demanda cognitiva presentan diferencias en el recuerdo de L1 y L2. La dirección en la que esta diferencia se manifiesta refleja los recursos cognitivos necesarios para completar cada tarea: la evaluación de la intensidad emocional involucra señales contextuales, por lo que el recuerdo para L1 se vería beneficiado cuando éste se utiliza con mayor frecuencia que L2 ya que L1 tendría asociadas más claves del contexto. En cambio, la traducción requiere mayores esfuerzos para recuperar la información tanto en L1 como en L2 por lo que la novedad del estímulo en L2, y no así en L1, podría reforzar la huella mnémica visto y considerando que la novedad de los estímulos de modo general afecta su procesamiento, incrementándolo, lo que explicaría la mejora del recuerdo.

Siguiendo esta línea, Ferré et al., (2013) diseñaron dos estudios en los que las consignas requerían centrarse exclusivamente en las características morfológicas de las palabras y no en su contenido emocional. Para evaluar la memoria, los participantes BL observaron una lista de palabras positivas, negativas y neutras, y reportaron la cantidad de vocales (Estudio 1) o evaluaron su nivel de concretud (es decir, indicaron que tan abstracta o concreta era una palabra; Estudio 2). Posteriormente, todos realizaron una tarea de recuerdo libre. Los autores encontraron que en ambas tareas los sujetos tuvieron una mejor memoria para palabras positivas que negativas, pero sólo luego de evaluar los niveles de concretud, los participantes recordaron mayor cantidad de palabras en su L1 que su L2, resultado similar al hallado por Ayçiçeği-Dinn y Caldwel-Harris (2009).

Posteriormente, Ferré et al. (2019) diseñaron tres estudios en los cuales se indagaron si una codificación incidental (i.e., los participantes realizaron una tarea no relacionada a la memoria) o intencional (i.e., los participantes sabían que serían evaluados en tareas de memoria) modificaba el recuerdo de palabras emocionales. Con dicho objetivo, los investigadores convocaron participantes BL simultáneos de catalán y español, residiendo en Cataluña, España. Para evaluar la memoria, a los participantes se les presentó una lista de palabras en catalán y español, y se les solicitó que memoricen las palabras (Estudio 1) o que las lean en voz alta (Estudios 2 y 3). Luego de 5 minutos, 
todos los participantes realizaron una tarea de reconocimiento. En conjunto, los resultados de estos estudios indicaron que sólo una codificación incidental de la información mejoró el recuerdo para el catalán, pero no para el español, en el cual se encontró una mayor cantidad de errores (falsas alarmas). Los autores concluyeron que las palabras en catalán poseen una menor frecuencia y, por lo tanto, esta mejora se debería a la novedad del estímulo. Sin embargo, resultados previos (Ferré et al., 2013) también reportaron un mayor recuerdo para el catalán en participantes de la misma comunidad que indicaron mayor dominio en este idioma. Considerando que, en el estudio de Ferré et al. (2013), esta mejora en el catalán no se encontró en los participantes con mayor dominio de español (para quienes se esperaría que el catalán sea más novedoso), el efecto de novedad requiere mayor estudio.

En personas que sólo utilizan un idioma, las palabras emocionales son mejor recordadas que las palabras neutras (Kensinger y Corkin, 2003; Talmi, 2013). Sin embargo, estudios en población BL indicaron que la información emocional codificada en alguno de los dos idiomas no se ajustaría a estos patrones previamente encontrados en población monolingüe. Por ejemplo, Baumeister et al. (2017) evaluaron palabras emocionales (referentes a alegría y enojo) a través de una tarea de reconocimiento en BL secuenciales y se halló que las palabras emocionales eran más recordadas que las neutras únicamente en L1. En línea con los reportes de menor emocionalidad en L2, estos resultados indicarían que las palabras emocionales exhibidas en L2 no presentarían una mejora de la memoria.

Por otro lado, Ferré et al. (2010) evaluaron participantes BL simultáneos españolcatalán, con mayor dominancia en uno u otro idioma. Durante la codificación estudiaron la emocionalidad de las palabras y, posteriormente, se realizó una tarea de recuerdo libre. Los autores encontraron que, para los participantes con mayor dominio de catalán, las palabras emocionales (positivas y negativas) se recordaron más que las neutras en ambos idiomas. Los participantes con mayor dominio de español, por otro lado, recordaron mejor las palabras positivas que las neutras y las negativas cuando éstas se presentaron en catalán. En segundo lugar, cuando evaluaron participantes BL secuenciales español-inglés utilizando el mismo procedimiento, encontraron que sólo en inglés (L2) las palabras negativas fueron mejor recordadas que las neutras, mientras que las palabras positivas se recordaron mejor que las neutras tanto en español como en inglés. Los autores sostuvieron que estas discrepancias se deben a la diferencia en la adquisición de los idiomas, ya que, los BL secuenciales habrían aprendido su L2 en un contexto áulico mientras que los BL simultáneos de forma naturalista en sus entornos familiares. Este contraste habría promovido la asociación de L1 y L2 a experiencias emocionales tempranas para los BL simultáneos, que se encuentran ausentes en un aprendizaje áulico, afectando de ese modo el posterior recuerdo.

Aun así, las discrepancias entre los estudios de Baumeister et al. (2017) y Ferré et al. (2010) pueden deberse a la selección de estímulos, ya que los primeros autores limitaron las palabras positivas a aquellas que eran "alegres", y las negativas a 
aquellas referidas al "enojo". Mientras que los segundos utilizaron palabras positivas (agradables), negativas (desagradables) y neutras, independientemente de si se circunscriben o no a un grupo semántico. Esto sería relevante ya que estudios con poblaciones monolingües (ML) sugieren que no todas las palabras emocionales se procesan del mismo modo, por lo que podrían derivar en tipos de respuestas diferentes (Wu y Zhang, 2019).

Finalmente, sólo un estudio (Schroeder y Marian, 2012) examinó las diferencias entre grupos ML y BL con conocimiento de diversos idiomas. Este estudio se destaca por otros motivos: es el único que se centró en adultos mayores, utilizó estímulos visuales, y presentó variaciones tanto a nivel de la valencia como de la activación de los estímulos empleados. En este caso, los participantes observaron pasivamente imágenes emocionales y posteriormente realizaron una tarea de recuerdo libre. Los autores encontraron que el grupo BL recordó mayor cantidad de imágenes positivas, negativas y de mayor activación que el grupo ML. Para los autores, esto se debe a que, por un lado, el bilingüismo funciona como factor protector frente al declive cognitivo propio de la vejez y, por otro, cuando las demandas léxicas son menores (porque los estímulos son imágenes) se evitan posibles discrepancias entre la recuperación de información en L1 y L2, potenciando así la memoria.

Históricamente, la incógnita respecto a si la experiencia BL produce cambios en la codificación y posterior evocación de la información emocional arroja efectos mixtos (Anooshian y Hertel, 1994; Ayçiçeği y Harris, 2004). Los resultados recabados en este apartado también muestran inconsistencias; sin embargo, algunos factores pueden agruparse para explicar las divergencias. Por un lado, la edad en la que se adquirieron los idiomas puede ser uno de los motivos por los cuales la emocionalidad se recuerda de forma diferente en participantes BL secuenciales (Ayçiçeği-Dinn y Caldwel-Harris, 2009; Baumeister et al., 2017) y simultáneos (Ferré et al., 2010, 2013, 2019). Estos resultados sugieren que los participantes simultáneos podrían haber asociado a sus experiencias emocionales categorías en ambos idiomas durante la infancia temprana, mientras que los BL secuenciales sólo asociaron experiencias emocionales en L1 y, consecuentemente, mostrarían una preferencia para utilizar L1 en la vida adulta. No obstante, se requiere desarrollar mayor cantidad de estudios que exploren las características del recuerdo a lo largo del ciclo vital, especialmente en aquellos BL que deban utilizar tanto L1 como L2 en su vida adulta.

Por otro lado, el desempeño en las tareas de memoria varía de acuerdo a la consigna que se le asigne a dicha tarea: tareas incidentales y emocionales modulan diferencialmente L1 y L2, mientras que las tareas intencionales y no emocionales demostran una codificación y recuperación similar en L1 y L2 (Ferré et al., 2019).

En síntesis, los estudios expuestos indican que la edad de adquisición de cada idioma y la consigna que se le asigne a la tarea de memoria son fundamentales para comprender cómo el contenido emocional de los estímulos incide en el recuerdo de cada idioma. Respecto al primer factor abordado, los BL simultáneos y secuenciales mostraron diferencias en el recuerdo. Desde una perspectiva teórica (Dijkstra et 
al., 2019; Kroll et al., 2010), esto se sustenta sobre la base de que BL simultáneos construyen de forma conjunta el reservorio de palabras y sus significados para ambos idiomas, mientras que los BL secuenciales construyen el léxico para L2 sobre la mediación de L1, disminuyendo la carga emocional.

No obstante, la cantidad de estudios aún es limitada y el campo requiere de mayor exploración. Por ejemplo, el reconocimiento y la posterior evocación de palabras en L2 pueden involucrar el ingreso de información tanto visual como auditiva. Estudios recientes indican que la adquisición y el uso de una L2 modula las conexiones neurales en las vías auditivas (Vaquero et al., 2020), por lo que el abordaje de los efectos de estas modificaciones en la memoria podría ser un próximo camino de investigación. En segundo lugar, la representatividad poblacional en este campo también debe ser más explorada. Los hallazgos realizados por Ferré et al. (2010, 2013, 2019), en hablantes de español y de catalán, deberían ser contrastados con otros hablantes bilingües con dominio de diferentes idiomas para identificar si las diferencias encontradas en el recuerdo se dan por efecto específico del fenómeno estudiado (bilingüismo) o diferencias en la gramática de ambos idiomas.

\section{Conclusiones}

El objetivo de la presente revisión fue recopilar y describir los estudios empíricos que investigan el efecto de la participación en actividades y entrenamientos musicales, la realización de actividad física y el aprendizaje de una segunda lengua, sobre la memoria emocional. Aunque la temática de esta revisión presenta pocos antecedentes al respecto, los estudios aquí analizados permiten vislumbrar el potencial efecto que poseen estos factores ambientales sobre un tipo de memoria asociado a la emoción.

Existe una clara diferencia dependiendo de la operacionalización de las variables independientes entre las tres temáticas abordadas. Se puede observar que la música y la actividad física presentan en su mayoría diseños de investigación con propuestas de intervenciones basadas, por un lado, en actividades musicales de percepción y producción, y por otro lado, en actividades aeróbicas o de resistencia, pero con escasos antecedentes sobre la influencia de un estilo de vida asociado a dichos factores. Por el contrario, el estudio centrado en la adquisición de una segunda lengua muestra el patrón opuesto, ya que hasta el momento no se propusieron investigaciones, de nuestro conocimiento, que pongan a prueba la participación focal o el aprendizaje de un segundo idioma en periodos cortos de tiempo sobre la memoria emocional.

En relación a las intervenciones ambientales implementadas para interferir alguna instancia de la formación de la huella mnémica, los estudios pueden dividirse de acuerdo a la fase intervenida: adquisición, consolidación, recuperación o reconsolidación del recuerdo.

En lo que concierne la intervención en la fase de adquisición de información, la actividad física generaría un estado de activación favorable que potenciaría el efecto obtenido por la observación de imágenes con contenido emocional (Keyan 
y Bryant, 2017b). Por otra parte, si un relato emocional negativo es presentado en simultáneo a una pieza musical de tipo relajante, la percepción auditiva impacta sobre la activación que el relato produce, lo que se ve reflejado en la disminución de contenido evocado en un testeo diferido si se lo compara con un relato neutro (Rickard et al., 2012). En ambos casos, el estado psicofisiológico inducido por las actividades testeadas justifica los resultados obtenidos. Sin embargo, al tratarse de estudios comportamentales resulta necesario contar con más investigaciones que respalden dichas sugerencias.

Con respecto a los tratamientos aplicados luego de la adquisición de información, es decir, durante la fase de consolidación, las investigaciones que indagaron el efecto de intervenciones musicales sobre diferentes tipos de memorias emocionales (visuales o verbales) mostraron ser eficaces a la hora de modular el recuerdo. Este resultado se verifica en estudios realizados con adultos jóvenes (Diaz Abrahan et al., 2018; Diaz Abrahan y Justel, 2019; Justel y Rubinstein, 2013; Justel et al., 2016) y con mayores (Diaz Abrahan et al., 2018; Justel et al., 2015), con propuestas tanto de percepción como de producción musical. Hay estudios que muestran que las intervenciones basadas en música, introducida de modo posterior a la codificación de información, genera cambios neuroquímicos (Rickard et al., 2012) y activa vías específicas en varias áreas del cerebro asociadas a comportamientos emocionales. En este sentido el arousal emocional inducido a partir de la participación de las diferentes propuestas musicales es la justificación con mayor sustento a la hora de explicar los resultados que evidencian aumento o disminución del material evocado en las tareas donde se evalúa la memoria.

En relación con la actividad física, la consolidación de la memoria fue la fase con mayor cantidad de resultados favorables producto de las intervenciones. Los estudios mencionados indican que la respuesta fisiológica relacionada al ejercicio es especialmente beneficiosa cuando se presenta en forma posterior a la codificación, sobreestimulando los circuitos neuronales vinculados a la amígdala (responsable del almacenamiento de recuerdos emocionales), previamente excitados por la exposición a los estímulos con contenido emocional (Keyan y Bryant, 2017a; Segal et al., 2012; Weinberg et al., 2014). La activación fisiológica también estaría presente en la modulación de la adquisición, sin embargo, aquí adquiere importancia un segundo aspecto: el momento de la implementación de la intervención y los tratamientos.

Las propuestas basadas en factores ambientales, pensadas con la intención de modular los diferentes estadios de la formación de la memoria, representan intervenciones que pueden ser pensadas, en principio, en dos contextos diferentes. Por un lado, en el contexto clínico hay que tener en cuenta los efectos de decremento o incremento que presentan estas intervenciones sobre la memoria. En relación al decremento, pueden ser implementadas para el abordaje de problemáticas como el estrés post traumático con el objetivo de disminuir la carga emocional de un evento adquirido en situaciones adversas. Con el efecto opuesto, y teniendo en cuenta las investigaciones que evidencian beneficios en la memoria, las intervenciones basadas en la música y la actividad física pueden pensarse como técnicas para el tratamiento 
de aquellas patologías con déficit en la memoria, como lo son por ejemplo los diferentes tipos de demencias. El segundo contexto está vinculado a la educación, ambiente donde los tres factores indagados en la presente revisión conforman áreas dentro de la currícula educativa que podrían implementarse con el objetivo de reforzar los aprendizajes diarios educativos. Las investigaciones presentadas sobre música y actividad física permiten esbozar ideas sobre esta aplicabilidad. Sin embargo, el bilingüismo carece de antecedentes como intervención focal, temática que en nuestra opinión resultan de suma importancia.

El segundo enfoque reportado en esta revisión estuvo relacionado con la investigación del efecto de los factores ambientales tomados como características del estilo de vida de los participantes, perspectiva bajo la cual los participantes podrían categorizarse como músicos, deportistas o sujetos bilingües.

Bajo esta mirada, el BL es la temática que más estudios presenta, a diferencia de la música y la actividad física. El BL es definido exclusivamente como un factor presente a priori en los participantes, ya que se trata de personas adultas que ya han adquirido dos o más idiomas. Aquí, el factor de interés para los investigadores es la diferencia entre ellos. Los estudios sondeados indican que la principal diferencia entre la codificación y la recuperación de información emocional en L1 y L2 se debe a la tarea propuesta y a la edad en la que se adquirieron los idiomas. La información emocional presentada en el idioma materno tiene una preponderancia cuando los BL adquirieron su L2 de forma posterior a su L1. Sin embargo, la tarea que realice al momento de la codificación puede alterar este patrón (Ayçiçeği-Dinn y CaldwelHarris, 2009; Ferré et al., 2019).

Se observa, por lo tanto, que la mayoría de los estudios recabados presenta comparaciones intrasujeto (i.e., L1 vs L2). En cambio, sólo se halló un estudio que presenta comparaciones intersujeto en una tarea de memoria visual emocional. En este caso, el grupo BL mostró un mejor desempeño en la tarea de memoria que los ML (Schroeder y Marian, 2012). El hallazgo de estas diferencias abre las puertas a futuras investigaciones que diluciden si la existencia de más de un sistema lingüístico (BL) genera cambios en la memoria, comparada con la presencia de un sistema lingüístico único (ML).

Cuando se trata de entrenamiento musical como estilo de vida, es decir personas con cinco o más años de dedicación al estudio de la música, la memoria es una función que se ve afectada positivamente como consecuencia del aprendizaje musical (Talamini et al., 2018). Sin embargo, los resultados en relación a la memoria de tipo emocional no son tan robustos. Cuando se compara a los músicos con personas sin conocimiento musicales, los estudios muestran que existe un potencial efecto por parte de las habilidades adquiridas durante el entrenamiento musical que impacta sobre la memoria emocional verbal (Diaz Abrahan y Justel, 2019) y visual (Diaz Abrahan et al., 2018, Diaz Abrahan, Shifres et al., 2019), lo que se traduce en un aumento cuantitativo del material evocado en las tareas que evalúan el rendimiento mnémico. Este efecto puede explicarse ya que el aprendizaje de la música puede conferir ventajas 
cognitivas que van más allá del procesamiento de la música en sí, lo que se conoce como transferencia lejana (Schlaug et al., 2005). Empero, dentro de la literatura existen variables que repercuten diferencialmente a nivel cognitivo, como lo es por ejemplo la edad de inicio a la exposición musical (Elbert et al., 1995; Pantev et al., 1998), el tipo de instrumento en el cual los músicos se especializan (Justel y Diaz Abrahan, 2012), entre otros aspectos que no han sido contemplados en las investigaciones analizadas en esta revisión. Investigar el efecto diferencial de las características de esta población de músicos parece ser un campo potencial de futuros trabajos.

Finalmente, la temática de la actividad física presenta un sólo antecedente que indaga cómo un estilo de vida físicamente activo repercute en la memoria emocional. Este estudio establece que niveles altos de compromiso con la actividad repercuten positivamente en la memoria emocional (Bossio y Justel, 2018). Sin embargo, esta parece ser un campo novedoso en la literatura que requiere mayor desarrollo.

De modo general, y pensando en los tres factores analizados, se advierten limitaciones que pueden resolverse en futuras investigaciones. En principio, todos los artículos desarrollados utilizaron imágenes o palabras emocionales y /o neutras como estímulos que conformaron los protocolos de adquisición de información. En este sentido, sería interesante el trabajo y la evaluación de tareas ecológicas, asociadas a los contextos educativos y clínicos donde se podrían aplicar estas propuestas.

Por otra parte, cabe destacar que, en gran medida, los estudios contaron únicamente con la participación de adultos jóvenesy adultos mayores, aspecto que deja en evidencia la escasez de investigaciones dirigidas a la población infantil, o de adultos con déficit mnésico, temática que cuenta con un solo trabajo sobre actividad física (Segal et al., 2012). Si bien existen antecedentes que, trabajando con entrenamientos físicamente activantes y niños de diferentes edades, hallaron beneficios en la memoria de trabajo, destreza inhibitoria y flexibilidad cognitiva (Jaschke et al., 2018; Roden et al., 2013; Saarikivi et al., 2016), la evaluación de la memoria emocional en población infantil es un tema que presenta una única referencia ligada a entrenamiento musical de corto plazo (Benitez et al., 2018). A su vez, se observa una escasez de investigaciones que indaguen los procesos de adquisición y recuperación de información emocional en niños BL, lo cual podría echar luz sobre sobre las relaciones entre lenguaje, emoción y memoria en el desarrollo, por ejemplo, indagando la evolución de los conceptos emocionales en niños inmersos en contextos L1 y L2.

Si bien la mayoría de los estudios focales basados en música y actividad física arrojaron resultados favorables, existe una gran cantidad de estudios que trabajan con entrenamientos sostenidos en el tiempo con beneficios en diferentes funciones cognitivas (Hamer et al., 2018; Hennessy et al., 2019; Woumans et al., 2016). Sería interesante tomar esta perspectiva de trabajo, con un entrenamiento de medio o largo plazo, e identificar su posible efecto sobre la memoria emocional. Por el contrario, adquirir un buen dominio de un segundo idioma es una tarea que suele durar años, por lo que no se han realizado intervenciones focales en el área de la memoria emocional. En este sentido, realizar investigaciones con estudiantes de idiomas extranjeros 
podría salvar la ausencia de este tipo de estudios sobre la memoria emocional.

Los tres factores desarrollados en la presente revisión muestran potencialidades en cuando a la modulación y a la relación con la memoria emocional, cada uno de ellos con limitaciones que se han identificado y descrito, con el fin de plantear futuros caminos de investigación. Cada una de las intervenciones se caracterizan por ser propuestas con un alto grado de aplicabilidad debido a su accesibilidad y bajo costo, la flexibilidad que presentan al ser adaptadas a diferentes contextos educativos, recreativos y clínicos así como también a diferentes poblaciones, y por ser consideradas como intervenciones no invasivas. Estas características y los hallazgos destacados en los estudios de esta revisión permiten pensar a la música, la actividad física y la adquisición de una segunda lengua como temáticas de relevancia clínica y educativa en lo que respecta a la comprensión de los mecanismos de la memoria, a la elaboración de estrategias y tratamientos que permitan no sólo mejorar los procesos de aprendizaje y memoria, sino también abordar problemáticas y déficits asociados a la memoria emocional donde es necesario lograr una disminución del recuerdo o del impacto emocional asociado al mismo. La participación en actividades musicales y físicas de tipo focal, así como el aprendizaje musical o de un segundo idioma parecen ser propuestas pertinentes para ser implementadas en programas de estimulación y rehabilitación de los procesos de aprendizaje y memoria. Cada una de las intervenciones abordadas en esta revisión modularía la memoria emocional bajo ciertas metodologías de implementación. Sin embargo, resulta necesario contar con más estudios para darle mayor sustento al uso de la música, la actividad física y la adquisición de un segundo idioma como moduladores de los procesos de memoria. 


\section{Referencias}

Andreano, J., Arjomandi, H., y Cahill, L. (2008) Menstrual cycle modulation of the relationship between cortisol and long-term memory. Psychoneuroendocrinology, 33(6), 874-882. HTTPS://DOI.ORG/10.1016/J.PSYNEUEN.2008.03.009

Anooshian, J. L., y Hertel, P. T. (1994). Emotionality in free recall: Language specificity in bilingual memory. Cognition and Emotion, 8, 503-514. HTTPS://DOI.ORG/10.1080/02699939408408956.

Altenmüller, E., y Schlaug, G. (2015). Apollo's gift: new aspects of neurologic music therapy. Progress in Brain Research, 217, 237-52. HTTPs://DOI. ORG/10.1016/BS.PBR.2014.11.029

Armstrong, N., y Welsman, J. (2007). Aerobic fitness: What are we measuring? Medicine and Sport Science, 50, 5-25. HTTPS://DOI.ORG/10.1159/000101073

Atkinson, R. C., y Shiffrin, R. M. (1971). The control of short-term memory. Scientific American, 225(2), 82-90. HTTPS://DOI.ORG/10.1038/ SCIENTIFICAMERICANO $871-82$

Ayçiçeği-Dinn, A., y Caldwell-Harris, C. L. (2009) Emotion-memory effects in bilingual speakers: A levels-of-processing approach. Bilingualism: Language and Cognition, 12(3), 291-303. нттPs:// DOI.ORG/10.1017/s1366728909990125

Ayçiçeği, A., y Harris, C. (2004). Bilinguals' recall and recognition of emotion words. Cognition and Emotion, 18(7), 977-987. HTTPs://DOI. ORG/10.1080/02699930341000301

Baumeister, J. C., Foroni, F., Conrad, M., Rumiati, R. I., y Winkielman, P. (2017). Embodiment and emotional memory in first vs. second language. Frontiers in Psychology, 8. 394 . HTTPS://DOI. ORG/10.3389/FPSYG.2017.00394

Benítez, M., Diaz Abrahan, V., Sarli, L., Bossio, M. y Justel, N. (2018). Las clases de música mejoran la memoria en niños prescolares. Panamerican Journal of Neuropsychology, 12(2), 366-387. HTTPS://DOI.ORG/10.7714/CNPS/12.2.207

Bermúdez-Rattoni, F., y Prado-Alcalá, R. (2001) Memoria. ¿En dónde está y cómo se forma? Trillas.

Bossio, M., y Justel, N. (2018). Impacto de un estilo de vida activo sobre la memoria emocional. Acción Psicológica, 15(1), 39-56. HтTPs://DOI. ORG/10.5944/AP.15.1.21446

Bradley, M. M., Greenwald, M. K., Petry, M. C., y Lang, P. J. (1992). Remembering pictures: Pleasure and arousal in memory. Journal of Experimental Psychology: Learning, Memory, and Cognition, 18(2), 379-390. HTTPS://DOI.ORG/10.1037/02787393.18.2.379
Cahill, L., y McGaugh, J. L. (1995). A novel demonstration of enhanced memory associated with emotional arousal. Consciousness and Cognition, 4(4), 410-421. HTTPs://DOI. ORG/10.1006/CCOG.1995.1048

Cahill, L., y McGaugh, J. L. (1998). Mechanisms of emotional arousal and lasting declarative memory. Trends in Neuroscience, 21(7), 294-299. HTTPS://DOI.ORG/10.1016/s0166-2236(97)01214-9

Cahill, L., y van Stegeren, A. (2003). Sex-related impairment of memory for emotional events with b-adrenergic blockade. Neurobiology of Learning and Memory, 79(1), 81-88. HTTPS://DOI. ORG/10.1016/s1074- 7427(02)00019-9

Chanda, M., y Levitin, D. (2013). The neurochemistry of music. Trends in Cognitive Sciences, 17(4), 179-193. HTTPS://DX.DOI.ORG/10.1016/J.TICS.2013.02.007

Chuang, L.-Y., Hung, H.-Y., Huang, C.-J., Chang, Y.K., y Hung, T.-M. (2015). A 3-month intervention of Dance Dance Revolution improves interference control in elderly females: a preliminary investigation. Experimental Brain Research, 233(4), 1181-1188. HTTPS://DOI.ORG/10.1007/ s00221-015-4196-X

Christie, G. J., Hamilton, T., Manor, B. D., Farb, N. A. S., Farzan, F., Sixsmith, A. ,... Moreno, S. (2017). Do lifestyle activities protect against cognitive decline in aging? A Review. Frontiers in Aging Neuroscience, 9, 381. HTTPS://DOI.ORG/10.3389/FNAGI.2017.00381

Clark, I. N., Baker, F., y Taylor, B. (2013). The modulating effects of music listening on healthrelated exercise and physical activity in adults: a systematic review and narrative synthesis. Nordic Journal of Music Therapy, 25(1), 76-104. HтTPs:// DOI.ORG/10.1080/08098131.2015.1008558

Cordon, I. M., Melinder, A. M. D., Goodman, G. S., y Edelstein, R. S. (2013). Children's and adults' memory for emotional pictures: Examining age-related patterns using the Developmental Affective Photo System. Journal of Experimental Child Psychology, 114(2), 339-356. HTtps://DoI. ORG/10.1016/J.JECP.2012.08.004

Diaz Abrahan, V., Bossio, M., y Justel, N. (2019). Hacia un envejecimiento saludable: una revisión sistemática sobe la música y el ejercicio físico como factores moduladores. Actualidades en Psicología, 33(127), 113-141. HTTPs://DoI. ORG/10.15517/AP.V33I127.34975

Diaz Abrahan, V., y Justel, N. (2019). Uso de la música para modular la memoria: Una revisión sistemática. Revista Iberoamericana de Psicología, 12(2), $39-50$. 
Diaz Abrahan, V., y Justel, N. (2019). Propuestas musicales para modular la memoria verbal emocional de adultos jóvenes con o sin entrenamiento musical. Epistemus. Revista de estudios en Música, Cognición y Cultura, 7(1), 4969. HTTPS://DOI.ORG/10.24215/18530494E003

Diaz Abrahan, V., Shifres, F., y Justel, N. (2018). Musical improvisation modulates emotional memory. Psychology of Music, 9, 1-16. HтTPs:// DOI.ORG/10.1177/0305735618810793

Diaz Abrahan, V., Shifres, F., y Justel, N. (2019). Cognitive benefits from a musical activity in older adults. Frontiers in Psychology, 10, 652. HTTPS://DOI.ORG/10.14349/SUMAPSI2012.1234

Diekelmann, S., y Born, J. (2010). The memory function of sleep. Nature Reviews Neurocience, 11(2), 114-26. HTTPS://DOI.ORG/10.1038/NRN2762

Dijkstra, T., Wahl, A., Buytenhuijs, F., Van Halem, N., Al-jibouri, Z., De Korte, M., y Rekké, S. (2019). Multilink: A computational model for bilingual word recognition and word translation. Bilingualism: Language and Cognition, 22(4), 657679. HTTPS://DOI.ORG/10.1017/s1366728918000287

Elbert, T., Pantev, C., Wienbruch, C., Rockstroh, B., y Taub, E. (1995). Increased Cortical Representation of the Fingers of the Left Hand in String Players. Science, 270(5234), 305-307. HTTPS://DOI.ORG/10.1126/SCIENCE.270.5234.305

Erickson, K. I., Voss, M. W., Prakash, R. S., Basak, C., Szabo, A., Chaddock, L., ... Kramer, A. F. (2011). Exercise training increases size of hippocampus and improves memory. Proceedings of the National Academy of Sciences, 108(7), 3017-3022. HTTPS://DOI.ORG/10.1073/PNAS.1015950108

Erk, S., von Kalckreuth, A., y Walter, H. (2010). Neural longterm effects of emotion regulation on episodic memory processes. Neuropsychologia, 48(4), 989-996. HTTPS://DOI.ORG/10.1016/J. NEUROPSYCHOLOGIA.2009.11.022

Ferré, P., Comesaña, M., y Guasch, M. (2019). Emotional content and source memory for language: Impairment in an incidental encoding task. Frontiers in Psychology, 10. 65. HTTPS://DOI. ORG/10.3389/FPSYG.2019.00065

Ferré, P., García, T., Fraga, I., Sánchez-Casas, R., y Molero, M. (2010). Memory for emotional words in bilinguals: Do words have the same emotional intensity in the first and in the second language? Cognition and Emotion, 24(5), 760-785. HTTPs:// DOI.ORG/10.1080/02699930902985779

Ferré, P., Sánchez-Casas, R., y Fraga, I. (2013). Memory for emotional words in the first and the second language. Bilingualism, 16(3), 495-507. HTTPS://DOI.ORG/10.1017/S1366728912000314
Ferreri, L., y Rodriguez-Fornells, A. (2017). Musicrelate rewards responses predict episodic memory performance. Experimental Brain Research, 235(12), 3721-3731. HTTPS://DOI.ORG/10.1007/ S00221-017-5095-0

Francis, W. S. y Gutiérrez, M. (2012). Bilingual recognition memory: Stronger performance but weaker levels-of-processing effects in the less fluent language. Memory \& Cognition, 40(3), 496 - 503. HTtPs://DOI.ORG/10.3758/s13421-011-01633

Franklin, M. S., Moore, K. S., Yip, C. Y., Jonides, J., Rattray, K., y Moher, J. (2008). The effects of musical training on verbal memory. Psychology of Music, 36(3), 353-365. HTTPs://DOI. ORG/10.1177/0305735607086044

Frutos-Lucas, J., López-Sanz, D., Zuluaga, P., Rodríguez-Rojo, I. C., Luna, R., López, M. E., ... Fernández, A. (2018). Physical activity effects on the individual alpha peak frequency of older adults with and without genetic risk factors for Alzheimer's Disease: A MEG study. Clinical Neurophysiology, 129(9), 1981-1989. HTTPS://DOI. ORG/10.1016/J.CLINPH.2018.06.026

Garber, C.E., Blissmer, B., Deschenes, M. R., Franklin, B. A., Lamonte, M. J., Lee, I.-M., ... Swain, D. P. (2011). Quantity and quality of exercise for developing and maintaining cardiorespiratory, musculoskeletal, and neuromotor fitness in apparently healthy adults. Medicine \& Science in Sports \& Exercise, 43(7), 1334-1359. HTTPS://DOI. ORG/10.1249/MSS.OBO13E318213FEFB

Gerry, D., Unrau, A., y Trainor L. J. (2012). Active music classes in infancy enhance musical, communicative and social development. Developmental Science 15(3), 398-407. нттрs:// DOI.ORG/10.1111/J.1467-7687.2012.01142.X

Grocke, D., y Wigram, T. (2007). Receptive methods in music therapy: Techniques and clinical applications for music therapy clinicians, educators and students. London / Philadelphia: Jessica Kingsley. Music Therapy Perspectives, 25(2), 127-129. HTTPS://DOI.ORG/10.1093/ MTP/25.2.127

Grosjean, F. (2008). Studying bilinguals. Oxford University Press.

Grosjean, F. (2013). Bilinguals: A short introduction. En F. Grosjean y P. Li (Eds.). The Psycholinguistics of Bilingualism (pp. 5-25). Wiley-Blackwell.

Hamer, M., Muniz Terrera, G., y Demakakos, P. (2018). Physical activity and trajectories in cognitive function: English longitudinal study of ageing. Journal of Epidemiology and Community Health, 72(6), 477-483. HTTPs://DOI.ORG/10.1136/ JECH-2017-210228 
Haranto, A., y Yang, H. (2016). Disparate bilingual experiences modulate task-switching advantages: A diffusion-model analysis of the effects of interactional context on switch costs. Cognition, 150, 10-19. HTTPS://DOI.ORG/10.1016/J. COGNITION.2016.01.016

Hennessy, S. L., Sachs, M. E., Ilari, B., y Habibi, A (2019). Effects of music training on inhibitory control and associated neural networks in schoolaged children: A longitudinal study. Frontiers in Neuroscience, 13. HTTPs://DOI.ORG/10.3389/ FNINS.2019.01080

Hogan, M., Kiefer, M., Kubesch, S., Collins, P., Kilmartin, L., y Brosnan, M. (2013). The interactive effects of physical fitness and acute aerobic exercise on electrophysiological coherence and cognitive performance in adolescents. Experimental Brain Research, 229(1), 85-96. HTTPS://DOI.ORG/10.1007/so0221-013-3595-0

Hyde, K., Lerch, J., Norton, A., Forgeard, M., Winner, E., Evans, A., y Schlaug, G. (2009). Musical training shapes structural brain development. The Journal of Neuroscience, 29(10), 3019-3025. HTTPS://DOI. ORG/10.1523/JNEUROSCI.5118-08.2009

Jaschke, A. C., Honing, H., y Scherder, E. J. A. (2018) Longitudinal analysis of music education on executive functions in primary school children. Frontiers in Neuroscience, 12. HTTPs://DOI. ORG/10.3389/FNINS.2018.00103

Jentschke, S., y Koelsch, S. (2009). Musical training modulates the development of syntax processing in children. NeuroImage, 47(2), 735-744. HTTPs:// DOI.ORG/10.1016/J.NEUROIMAGE.2009.04.090

Judde, S. y Rickard, N. (2010). The effect of postlearning presentation of music on long term word list retention. Neurobiology of Learning and Memory, 94, 13-20. HTTPS://DOI.ORG/10.1016/J. NLM.2010.03.002

Justel, N., y Diaz Abrahan, V. (2012). Plasticidad cerebral: Participación del entrenamiento musical. Suma Psicológica, 17(2), 97-108. HTTPs:// DOI.ORG/10.14349/SUMAPSI2012.1234

Justel N., Diaz Abrahan, V., Castro, C., y Rubinstein W., (2016). Efecto de la música sobre la memoria emocional verbal. Anuario de Investigaciones, XXI.

Justel, N., O'Conor, J. y Rubinstein, W. (2015) Emotional memory modulation through music in older people: A preliminary study. Interdisciplinaria, 32(2), 247-259.

Justel, N., Psyrdellis, M., y Ruetti, E. (2013) Modulación de la memoria emocional: Una revisión de los principales factores que afectan los recuerdos. Suma Psicológica, 20(2), 163-174 HTTPS://DOI.ORG/10.14349/SUMAPSI2013.1276
Justel, N., y Rubinstein, W. (2013). La exposición a la música favorece la consolidación de los recuerdos. Boletín de Psicología, 109, 73-83.

Kamijo, K., Hayashi, Y., Sakai, T., Yahiro, T., Tanaka, K., y Nishihira, Y. (2009). Acute effects of aerobic exercise on cognitive function in older adults. Journal of Gerontology: Psychological Sciences, 64B(3), 356-363. HTTPS://DOI.ORG/10.1093/ GERONB/GBPO3O

Kennedy, G., Hardman, R. J., Macpherson, H., Scholey, A. B., y Pipingas, A. (2016). How does exercise reduce the rate of age-associated cognitive decline? A review of potential mechanisms. Journal of Alzheimer's Disease, 55(1), 1-18. HTTPS://DOI.ORG/10.3233/JAD-160665

Kensinger, E. A., y Corkin, S. (2003). Memory enhancement for emotional words: Are emotional words more vividly remembered than neutral words? Memory \& Cognition, 31(8), 1169-1180. HTTPS://DOI.ORG/10.3758/BF03195800

Keyan, D., y Bryant, R. A. (2017a). Brief exercise enhances intrusive memories of traumatic stimuli. Neurobiology of Learning and Memory, 141(3), 9-13. HTTPS://DOI.ORG/10.1016/J.NLM.2017.03.012

Keyan, D., y Bryant, R. A. (2017b). Role of BDNF val66met polymorphism in modulating exercised-induced emotional memories. Psychoneuroendocrinology, 77, 150-157. нтTPS:// DOI.ORG/10.1016/J.PSYNEUEN.2016.12.013

Keyan, D., y Bryant, R. A. (2017c). Acute physical exercise in humans enhances reconsolidation of emotional memories. Psychoneuroendocrinology, 86(8), 144-151. HTTPS://DOI.ORG/10.1016/J. PSYNEUEN.2017.09.019

Knight, W. E. J., y Rickard, N. S. (2001). Relaxing music prevents stress-induced increases in subjective anxiety, systolic blood pressure, and heart rate in healthy males and females. Journal of Music Therapy, 38(4), 254-272. HTtPs://DOI. ORG/10.1093/JMT/38.4.254

Kotilahti, K., Nissilä, I., Näsi, T., Lipiäinen, L., Noponen, T., Meriläinen, P., ... Fellman, V. (2009). Hemodynamic responses to speech and music in newborn infants. Human Brain Mapping, 31, 595 603. HTTPS://DOI.ORG/10.1002/HBM.20890

Kroll, J. F., van Hell, J. G., Tokowicz, N., y Green, D. W. (2010). The Revised Hierarchical Model: A critical review and assessment. Bilingualism: Language and Cognition, 13(3), 373-381. HTTPS:// DOI.ORG/10.1017/s136672891000009X

LaBar, K. S., y Cabeza, R. (2006). Cognitive neuroscience of emotional memory. Nature Reviews Neuroscience, 7(1), 54-64. HTtPs://DOI. ORG/10.1038/NRN1825 
Lang, P. J., Bradley, M. M., y Cuthbert, B. N. (1995). International affective picture system (IAPS): Affective ratings of pictures and instruction manual. Technical Report A-6. University of Florida.

Lang, P. J., Greenwald, M. K., Bradley, M. M., y Hamm, A. O. (1993). Looking at pictures: affective, facial, visceral, and behavioral reactions. Psychophysiology, 30, 261-273. HтT Ps:// DOI.ORG/10.1111/J.1469-8986.1993.TB03352.X

McGaugh, J. L. (2002). Memory consolidation and the amygdala: a systems perspective. Trends in Neurosciences, 25(9), 456-461. HTTPs://DOI. ORG/10.1016/so166-2236(02)02211-7

McGaugh, J. L., y Roozendaal, B. (2009). Emotional hormones and memory modulation. Encyclopedia of Neuroscience, 933-940. HTTPs:// DOI.ORG/10.1016/B978-008045046-9.00849-4

Milner, B., Squire, L. R., y Kandel, E. R. (1998). Cognitive neuroscience and the study of memory. Neuron, 20(3), 445-468. HTTPs://DOI. ORG/10.1016/so896-6273(00)80987-3

Moayeri, S., Cahill, L., Jin, I., y Potkin, S. (2010). Relative sparing of emotionally influenced memory in Alzheimer's disease. Neuroreport, 11(4), 653-655. HTTPS://DOI. ORG/10.1097/00001756-200003200-00001

Musiek, F. E., Shinn, J. B., Jirsa, R., Bamiou, D. E., Baran, J. A., y Zaida, E. (2005). GIN (GapsIn-Noise) test performance in subjects with confirmed central auditory nervous system involvement. Ear Hear, 26(6), 608-618. нттрs:// DOI.ORG/10.1097/01.AUD.0000188069.80699.41

Nieminen, S., Istók, E., Brattico, E., Tervaniemi, M., y Huotilainen, M. (2011). The development of aesthetic responses to music and their underlying neural and psychological mechanisms. Cortex, 47(9), 11381146. HTTPS://DOI.ORG/16/J.CORTEX.2011.05.008

Pantev, C., Oostenveld, R., Engelien, A., Ross, B., Roberts, L. E., y Hoke, M. (1998). Increased auditory cortical representation in musicians. Nature, 392(6678), 811-814. HTTPS://DOI.ORG/10.1038/33918

Pavlenko, A. (2005). Emotions and multilingualism. Cambridge University Press.

Pavlenko, A. (2012). Affective processing in bilingual speakers: Disembodied cognition? International Journal of Psychology, 47(6), 405-428. HтTPs:// DOI.ORG/10.1080/00207594.2012.743665

Piñeyro, M., Ferrer Monti, R. I., Díaz, H., Bueno, A. M., Bustos, S. G., y Molina, V. A. (2018). Positive emotional induction interferes with the reconsolidation of negative autobiographical memories, in women only. Neurobiology of Learning and Memory, 115, 508-5018. нтTPs:// DOI.ORG/10.1016/J.NLM.2018.08.003
Redondo, J., Fraga, I., Padrón, I., y Comesaña, M. (2007). The Spanish adaptation of ANEW (Affective Norms for English Words). Behavior Research Methods, 39(3), 600-605. HTTPS://DOI.ORG/10.3758/BF03193031

Rickard, N., Toukhsati, S., y Field S. (2005). The effect of music on cognitive performance: Insight from neurobiological and animal studies. Behavioral and Cognitive Neuroscience Reviews, 4(4), 235 261. HTTPS://DOI.ORG/10.1177/1534582305285869

Rickard, N. S., Wong, W. W., y Velik, L. (2012). Relaxingmusic countersheightened consolidation of emotional memory. Neurobiology of Learning and Memory, 97(2), 220-228. HTTPS://DOI. ORG/10.1016/J.NLM.2011.12.005

Roden, I., Grube, D., Bongard, S., y Kreutz, G. (2013). Does music training enhance working memory performance? Findings from a quasi-experimental longitudinal study. Psychology of Music, 42(2), 284298. HTTPS://DOI.ORG/10.1177/0305735612471239

Roozendaal, B., y McGaugh, J. L. (2011). Memory modulation. Behavioral Neuroscience, 125(6), 797-824. HTTPS://DOI.ORG/10.1037/A0026187

Ruetti, E., Justel, N., y Bentosela, M. (2009). Perspectivas clásicas y contemporáneas acerca de la memoria. Suma Psicológica, 16(1), 65-83. HTTPS://DOI.ORG/10.14349/SUMAPSI2009.96

Russell, J. (1980). A circumplex model of affect. Journal of Personality and Social Psychology, 39, 1161-1178.

Saarikivi, K., Putkinen, V., Tervaniemi, M., y Huotilainen, M. (2016). Cognitive flexibility modulates maturation and music-trainingrelated changes in neural sound discrimination. European Journal of Neuroscience, 44(2), 18151825. HTTPS://DOI.ORG/10.1111/EJN.13176

Sachs, M. E., Habibi, A., Damasio, A., y Kaplan, J. T. (2019). Dynamic intersubject neural synchronization reflects affective responses to sad music. NeuroImage, 116512. HTTPS://DOI. ORG/10.1016/J.NEUROIMAGE.2019.116512

Schlaug, G., Norton, A., Overy, K., y Winner, E. (2005). Effects of music training on the child's brain and cognitive development. Annals of New York Academy of Sciences, 1060(1), 219-230. HTTPS://DOI.ORG/10.1196/ANNALS.1360.015

Schroeder, S. R., y Marian, V. (2012). A bilingual advantage for episodic memory in older adults. Journal of Cognitive Psychology, 24(5), 591-601. HTTPS://DOI.ORG/10.1080/20445911.2012.669367

Segal, S. K., Cotman, C. W., y Cahill, L. F. (2012). Exercise-induced noradrenergic activation enhances memory consolidation in both normal aging and patients with amnestic mild cognitive impairment. Journal of Alzheimer's Disease, 32(4), 1011-1018. HTTPS://DOI.ORG/10.3233/JAD-2012-121078 
Sellami, M., Gasmi, M., Denham, J., Hayes, L. D., Stratton, D., Padulo, J., y Bragazzi, N. (2018). Effects of acute and chronic exercise on immunological parameters in the elderly aged: Can physical activity counteract the effects of aging? Frontiers in Immunology, 9. 2187. нттPs:// DOI.ORG/10.3389/FIMMU.2018.02187

Shields, G. S., Sazma, M. A., McCullough, A. M. y Yonelinas, A. P. (2017). The effects of acute stress on episodic memory: A meta-analysis and integrative review. Psychological Bulletin, 143(6), 636-675. HTTPS://DOI.ORG/10.1037/BUL0000100

Squire, L. R. (1987). Memory and brain. Oxford University Press.

Squire, L. R. (2004). Memory systems of the brain: A brief history and current perspective. Neurobiology of Learning and Memory, 82(3), 171177. HTTPS://DOI.ORG/10.1016/J.NLM.2004.06.005

Strong, J. V., y Mast, B. T. (2018). The cognitive functioning of older adult instrumental musicians and non-musicians. Aging, Neuropsychology, and Cognition, 26(3), 367-386. HTTPS://DOI.ORG/10.10 $80 / 13825585.2018 .1448356$

Talamini, F., Altoè, G., Carretti, B., y Grassi, M. (2018). Musicians have better memory than nonmusicians: A meta-analysis. PLoS ONE, 13(1), e0191776. HTTPS://DOI.ORG/10.1371/JOURNAL PONE.0191776

Talmi, D. (2013). Enhanced emotional memory: Cognitive and neural mechanisms. Current Directions in Psychological Science, 22(6), 430 436. HTTPS://DOI.ORG/10.1177/0963721413498893

Tambini, A., Rimmele, U., Phelps, E. A., y Davachi L., (2017). Emotional brain states carry over and enhance future memory formation. Nature Neurocience, 20(2), 271-278. HTTPS://DOI. ORG/10.1038/NN.4468

Tsai, C.-L., Wang, C.-H., Pan, C.-Y., y Chen, F.-C. (2015). The effects of long-term resistance exercise on the relationship between neurocognitive performance and GH, IGF-1, and homocysteine levels in the elderly. Frontiers in Behavioral Neuroscience, 9, 23. HTtPs://DoI.ORG/10.3389/ FNBEH.2015.00023

Tulving, E. (2002). Episodic memory: From mind to brain. Annual Review of Psychology, 53(1), 1-25. HTTPS://DOI.ORG/10.1146/ANNUREV. PSYCH.53.100901.135114
Vaquero, L., Ramos-Escobar, N., François, C., Penhune, V., y Rodríguez-Fornells, A. (2018). White-matter structural connectivity predicts short-term melody and rhythm learning in nonmusicians. NeuroImage, 181, 252-262. HTTPS:// DOI.ORG/10.1016/J.NEUROIMAGE.2018.06.054

Vaquero, L., Rousseau, P., Vozian, D., Klein, D., y Penhune, V. (2020). What you learn \& when you learn it: Impact of early bilingual \& music experience on the structural characteristics of auditory-motor pathways. NeuroImage, 213, 116689. HTTPS://DOI.ORG/10.1016/J. NEUROIMAGE.2020.116689

Wade, B., y Loprinzi, P. (2018). The experimental effects of acute exercise on long-term emotional memory. Journal of Clinical Medicine, 7(12), 486. HTTPS://DOI.ORG/10.3390/JCM7120486

Wamsley, E. (2019). Memory consolidation during rest. Trends in Cognitive Science, 23(3), 171-173. HTTPS://DOI.ORG/10.1016/J.TICS.2018.12.007

Wang, B., y Sun, B. (2016). Post-encoding emotional arousal enhances consolidation of item memory, but not reality-monitoring source memory. The Quarterly Journal of Experimental Psychology, 70(3), 461-472. HTTPS://DOI.ORG/10.1080/1747021 8.2015 .1134604

Weinberg, L., Hasni, A., Shinohara, M., y Duarte, A. (2014). A single bout of resistance exercise can enhance episodic memory performance. Acta Psychologica, 153, 13-19. HTTPs://DOI. ORG/10.1016/J.ACTPSY.2014.06.011

Woumans, E., Surmont, J., Struys, E., y Duyck, W. (2016). The longitudinal effect of bilingual immersion schooling on cognitive control and intelligence. Language Learning, 66(S2), 76-91. HTTPS://DOI.ORG/10.1111/LANG.12171

Yow, W. Q., y Li, X. (2015). Balanced bilingualism and early age of second language acquisition as the underlying mechanisms of a bilingual executive control advantage: Why variations in bilingual experiences matter. Frontiers in Psychology, 6, 164. HTTPS://DOI.ORG/10.3389/ FPSYG.2015.00164

Zatorre, R., Chen, J., y Penhune, V. (2007). When the brain plays music: Auditory-motor interactions in music perception and production. Nature Reviews, 8(7), 547-558. HTTPs://DOI.ORG/10.1038/ NRN2152 